\title{
Planificación territorial y ordenamiento jurídico: la construcción de la institución hospitalaria en la Buenos Aires higiénica
}

Territorial planning and legal system: the construction of the hospital institution in Buenos Aires hygienic

Gabriela Campari ${ }^{1}$

\section{Resumen}

La ciudad de Buenos Aires cristalizó sus formas de ordenamiento territorial, a partir de los instrumentos políticos que legitimaron el pensamiento higienista, mediante la aplicación de estructuras socioespaciales y sociopolíticas, que delinearon el espacio geográfico. En ese marco se definió un modelo hospitalario, que puso en marcha los modos de intervenir lo urbano, replicando una idea rectora ligada a un complejo arquitectónico con espacios y volúmenes racionalmente organizados, que articuló lo construido -pabellones- con senderos o galerías de vinculación y áreas verdes circundantes. En este sentido, el artículo se propone analizar el marco jurídico base que sustentó y reguló el espacio urbano y la higiene pública, y la incidencia de la institución hospitalaria, a partir de textos legales, memorias municipales y fuentes bibliográficas que sustentan los aportes conceptuales para el análisis geográfico; y exponer reflexiones sobre circunstancias que impactaron en un sector de la salud pública y transparentaron la controversia de intereses sobre el valor patrimonial del hospital pabellonal y su espacio verde, a fin de promover el debate para elaborar nuevas lecturas de la ciudad y repensar el planeamiento urbano a la luz del siglo XXI.

1 Licenciada en Planificación y Diseño del Paisaje de la Universidad de Buenos Aires (UBA). Docente Autorizado Universidad de Buenos Aires. Becaria Doctoral Facultad de Arquitectura, Diseño y Urbanismo, Secretaría de Ciencia y Técnica, UBA. Argentina.gecampari@yahoo.com.ar 
Palabras clave: Higiene, política de la salud, planificación urbana, paisaje, hospital.

\section{Abstract}

The city of Buenos Aires materialized its forms of land planning, from the political instruments that legitimized the hygienist thought, by applying socio-spatial and socio-political structures that defined geographical space. In this context was defined a hospital model, which launched the ways of urban intervention, replicating a main idea linked to an architectural complex with spaces and volumes rationally organized, which articulated the built pavilions- with the trails or galleries of linkage and surrounding green areas. In this sense, the article analyzes the basic legal framework that sustained and regulated urban space and public hygiene, and the incidence of the hospital institution, from legal texts, municipal reports and bibliographic sources, that support the conceptual contributions to geographic analysis; and express thoughts about events that impacted in a public health sector and showed the interests controversy on heritage value of the hospital with pavilions and its green space, in order to promote discussion to elaborate new readings of the city and rethink urban planning in light of the $21^{\text {st }}$ century.

Keywords: Hygiene, health policy, urban planning, landscape, hospitals. 


\section{Introducción}

La idea de construir una Buenos Aires higiénica, como modelo urbano de finales del siglo XIX, fue complejizando las representaciones sociales en las formas de ver la ciudad. Esa organización espacial, definida por Capel (1975) como un producto social, modelado y condicionado por las relaciones socioeconómicas y políticas contextuales, tuvo su incidencia en el tratamiento de los espacios verdes de las instituciones hospitalarias, como parte del plan de higiene pública llevado a cabo para el bienestar de la sociedad. Estas medidas siguieron los modelos europeos del utopismo reformista como los de Fourier y Garnier (CEAL, 1991), que bajo una mirada crítica de la situación social, examinaron la ciudad industrializada desde el desorden urbano. Asimismo este concepto de ordenamiento espacial, estuvo regido por los tratados sobre higiene pública y privada (Lévy, 1877; Giné \& Partagás, 1875), por manuales vinculados al higienismo y a las políticas públicas implementadas en los establecimientos sanitarios europeos, que se adecuaron y ampliaron a las necesidades y manejos del quehacer nacional, determinando reglas de uso legitimadas desde el poder político, para dar forma a las diversas obras hospitalarias. Estos escritos trazaron las pautas instrumentales ligadas al par dialéctico salud-enfermedad, que determinaron modos racionalizados de proceder y de construir el habitar, que rescató la idea organicista, en la cual las partes quedaban integradas en un todo, dando forma a la obra como totalidad orgánica con un funcionamiento utilitario y compositivo de conjunto.

En el ámbito nacional, los paradigmas higienistas se instrumentaron a partir de la institucionalización de Buenos Aires como capital de la República, circunstancia que dio lugar a reglamentar una estructura municipal. Cuidar la ciudad implicaba primordialmente, conservar la salud de sus pobladores y prevenirlos de las enfermedades infectocontagiosas. Esta preocupación, sostenida en el grado de insalubridad e infección que exhibía Buenos Aires, determinó la aplicación de reglas profilácticas que organizaran el adecuado desenvolvimiento en el ámbito urbano. En este contexto, Buenos Aires comenzaría a jugar un papel importante en las definiciones del espacio urbano, tanto público como privado, que requirieron el planteo de alternativas higiénicas de planificación, que elevasen la calidad de vida de sus habitantes y brindasen mejores respuestas a los problemas de hacinamiento y enfermedades contagiosas que repercutían a nivel mundial.

La tradición del pensamiento politécnico de la École Polytechnique de París, influenció el quehacer arquitectónico desde su significación por los temas y programas que se abordaron en la gestión pública. Vinculado a la ingeniería social, se estandarizaron criterios de especialización, definiendo una ciudad industrialmente organizada y ordenada, con capacidad económica, que pudiera dar respuesta a la aplicación de nuevas tecnologías y el consecuente incremento de la productividad y del empleo pro- 
letario. En esta adopción de nuevas formas y funciones, lo hospitalario reflejó un orden que contempló, desde el pensamiento higienista, los modos de producción de estos establecimientos al servicio de la salud. En este sentido, el presente artículo analizó la interacción entre el discurso médico, la práctica pública de la higiene y la intervención paisajística en los hospitales de Buenos Aires. Desde el punto de vista metodológico, se analizaron fuentes escritas como la Ley Orgánica de la Municipalidad de la Capital y las memorias municipales vinculadas al contexto histórico del higienismo y las políticas públicas implementadas en la ciudad, como así también aportes conceptuales de fuentes bibliográficas para el análisis dinámico del paisaje urbano. A fin de organizar el escrito, se conformaron tres capítulos: el primero da cuenta de la institucionalización de la capital de la República y la sanción de reglamentaciones que dieron marco jurídico a las cuestiones referidas a la higiene, salud y obras públicas en el espacio urbano. En un segundo capítulo, se hace referencia a la Buenos Aires higiénica y el estado de infección que prevalecía en la ciudad con base en el Censo de 1904, como así también las prácticas en la higiene urbana implementadas en la reorganización espacial del servicio hospitalario. En tercer lugar, se analizan las características compositivas que dieron morfología al paisaje hospitalario. Por último, extendemos algunas reflexiones que permitan reconsiderar la idea higiénica del conjunto hospitalario bajo la mirada del siglo XXI, a fin de que los revalorice como espacios sani- tarios, instalando nuevos debates sobre la salud de la población y el ambiente, cuestiones que en las últimas décadas han adquirido una mayor importancia e interrelación a escala global.

\section{De la capital de la República a la asistencia pública}

Una vez consolidada institucionalmente la ciudad de Buenos Aires como capital de la Nación (1880), el Congreso Nacional debió abocarse a estudiar y sancionar una ley dirigida a estructurar su régimen municipal. Luego de la presentación del proyecto del Poder Ejecutivo y la sanción de la Ley $\mathrm{N}^{\circ} 1029$ (Congreso de la Nación Argentina, 1880), se inició un nuevo estudio que dio lugar a la sanción, el 23 de octubre de 1882 , de la Ley Orgánica de la Municipalidad de la Capital de la República $\mathrm{N}^{\circ}$ 1260 (Congreso de la Nación Argentina, 1882) y (Honorable Concejo Deliberante, 1995). Esta norma constituyó un verdadero hito en la organización de la ciudad, y si bien fue modificada y adecuada a lo largo del tiempo a las transformaciones de Buenos Aires, su esencia se mantuvo inalterable destacando su jerarquía como instrumento legal. Evidentemente, la ciudad evolucionaba y crecía incesantemente, problematizando las cuestiones relativas a la infraestructura y a las condiciones dignas de habitabilidad, en especial para aquellos inmigrantes europeos recién llegados, que pasaban a formar parte de los sectores populares urbanos de una ciudad en pleno proceso de cambios políticos, so- 
ciales, económicos y urbanísticos, que reflejaba la complejidad de una gran urbe que había comenzado a dispersarse. Tan solo cuatro años después de la federalización del territorio capitalino, la Legislatura de la Provincia de Buenos Aires sancionó la Ley Provincial del 28 de octubre de 1884, que dispuso la cesión a la Nación de los territorios de los municipios de Belgrano y de San José de Flores (Figura 1). Ahora bien, tres años después el 28 de septiembre de
1887, la Legislatura Provincial dictó la Ley $N^{\circ} 1899$ (Congreso de la Provincia de Buenos Aires, 1887), rectificando, en una primera instancia, la incorporación de los municipios mencionados a la trama urbana de Buenos Aires, como así también el acto de cederle a la capital federal todo el territorio de Belgrano y Flores; resultando el ejido así conformado, el que integra hasta hoy el territorio de la Ciudad Autónoma de Buenos Aires (Figura 2).

Figura 1. Plano del territorio cedido a la Nación para el ensanche de la Capital Federal con indicación del límite definitivamente adoptado. Año 1888.

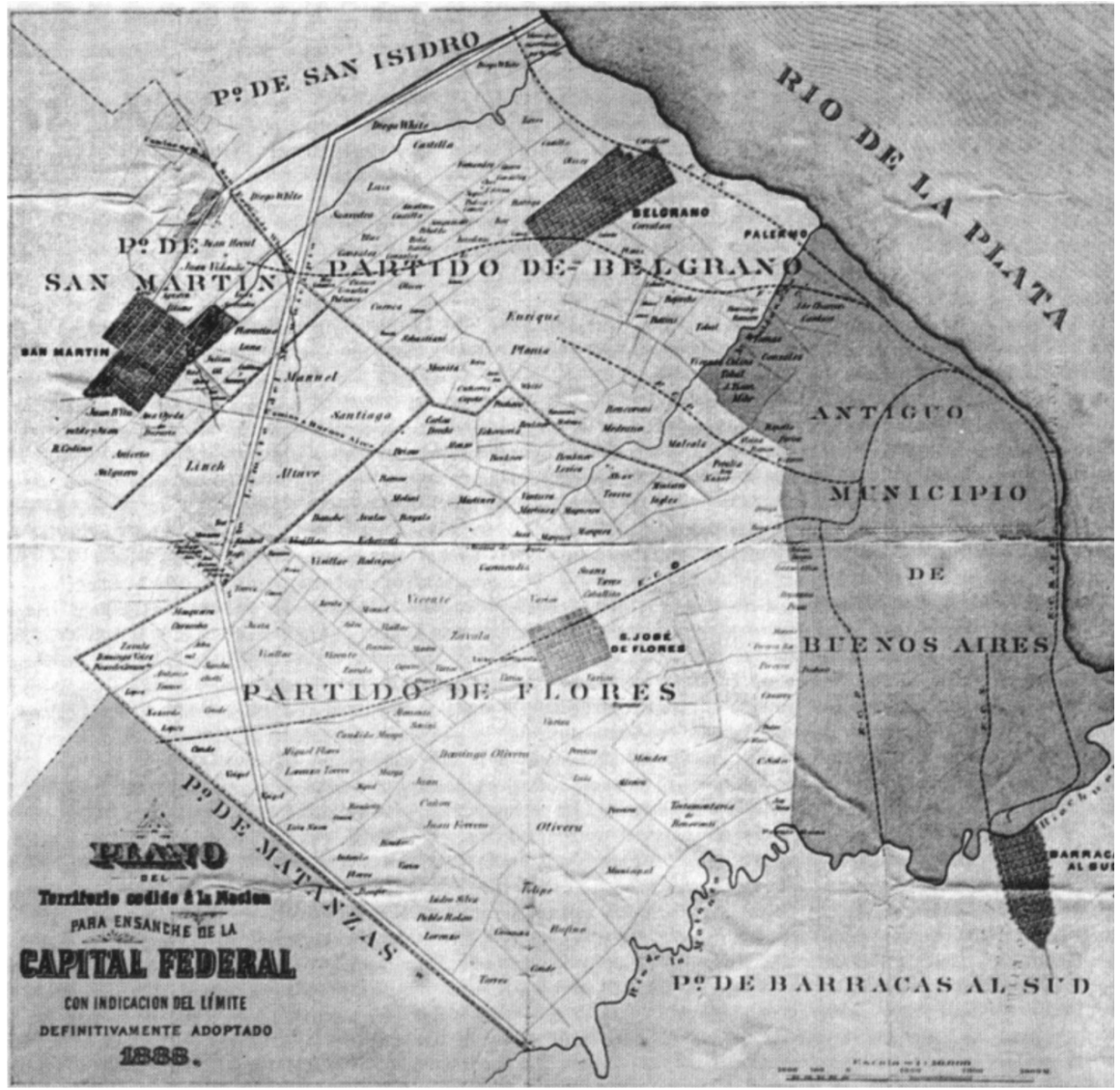

Fuente: Archivo Instituto Histórico de la Ciudad de Buenos Aires. 
Figura 2. Ciudad de Buenos Aires y Distrito Federal publicado por Pablo Ludwig. Año 1892. Esc. 1:35.000.

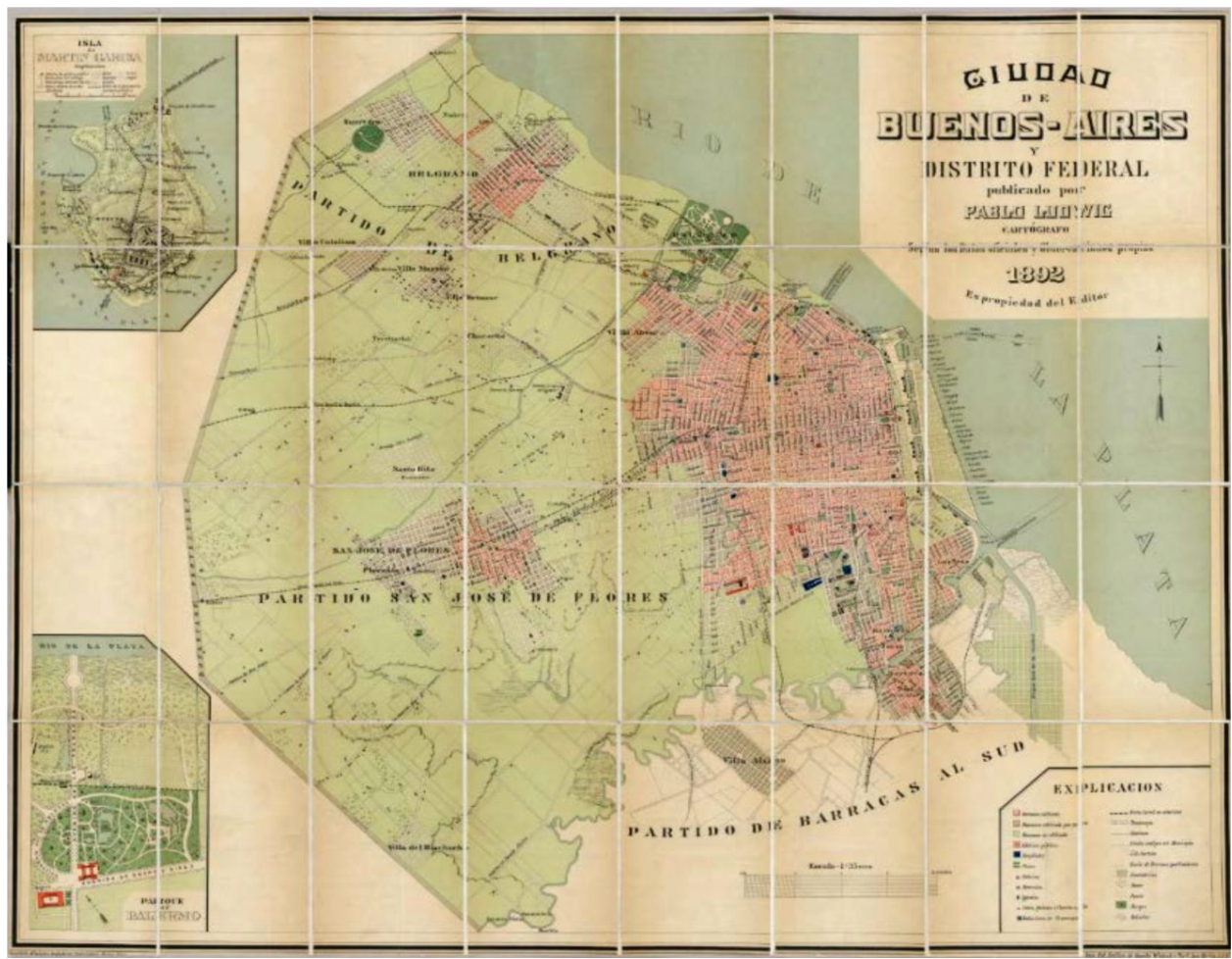

Fuente: Archivo Gobierno de la Ciudad de Buenos Aires. Ministerio de Desarrollo Urbano. Secretaría de Planeamiento.

En esta etapa de mutación del paisaje por cambios estructurales y funcionales de la sociedad (Santos, 1996), la ciudad contaba con un orden normativo que se ajustó a esos nuevos cambios e inquietudes emergentes que quedaron de manifiesto por su proceso de construcción ciudadana. No es casual que en la instancia del estudio y sanción de la Ley Orgánica, los antecedentes de las enfermedades epidémicas de cólera (1869) y fiebre amarilla (1871) acontecidas en Buenos Aires, hicieran cuestionar las condiciones en las que se encontraba la ciudad, y reglamentar aspectos referidos a la higiene urbana y la salud preventiva de la población, que resultaron ser pilares estructurales de las políticas públicas que se llevarían a cabo.

Conforme a la Ley Orgánica $\mathrm{N}^{\circ} 1260$ (Congreso de la Nación Argentina, 1882) y (Honorable Concejo Deliberante, 1995), el gobierno de la Municipalidad de la Capital de la República quedó integrado por un Concejo Deliberante y un Departamento Ejecutivo, encargados de dictar las medidas, ordenanzas 
y disposiciones, y ejercer la dirección y administración de las propiedades o intereses locales del municipio. Estas atribuciones quedaron referidas a tres secciones: Hacienda; Obras Públicas, y Seguridad, Higiene, Beneficencia y Moralidad Pública, dictaminando cada una de ellas sobre cuestiones que pugnaron en la idea de la construcción hospitalaria asociada a la organización del espacio urbano. En el caso de Hacienda ${ }^{2}$, se expresó la necesidad de aumentar la disponibilidad presupuestaria por medio de un organismo oficial y destinar lo recaudado al mantenimiento y formación de instituciones públicas, principalmente, en el ámbito de la salud. En ese orden, se creó una lotería pública cuyos beneficios se destinarían exclusivamente a subvencionar la Sociedad de Beneficencia, Hospicio de Dementes, asilos y demás establecimientos de esa clase.

Con relación a la sección de Obras Públicas $^{3}$ quedaron explicitadas las cuestiones del espacio urbano, ordenando el ensanche y apertura de calles, la fijación de la altura de los edificios particulares y de las delineaciones de la ciudad, el establecimiento de plazas, paseos y parques, autorizando la compra o expropiación de los terrenos necesarios a ese efecto y la construcción de drenajes y acueductos para la circulación de las aguas. En la misma sección quedó mencionada la provisión de servicios públicos -aguas corrientes-, la construc-

2 Cfme. Arts. $1^{\circ}, 43$ y 44 de la Ley $N^{\circ} 1260$ (Congreso de la Nación Argentina, 1882, p. 1021, 1024-1025).

3 Cfme. Art. 46, inc. $1^{\circ}$ a $3^{\circ}$ y $6^{\circ}$ (Congreso de la Nación Argentina, 1882, p. 1025). ción de caminos, puentes, desagües y calzadas, y lo referido al espacio público en cuanto a su equipamiento y restauración, y la construcción, conservación y mejora de edificios, monumentos públicos, paseos, plazas, empedrados, puentes, caminos y demás obras públicas municipales.

En la sección de Seguridad, Higiene ${ }^{4}$, Beneficencia y Moralidad Pública, se legislaron las atribuciones correspondientes al Concejo relacionadas con la higiene pública, entre ellas, las concernientes a: limpieza general del municipio, la desinfección del aire, aguas y habitaciones, la propagación de la vacuna y medios de hacerla obligatoria, la reglamentación higiénica de edificios públicos, casas de diversión y de inquilinato y de los establecimientos e industrias incómodas e insalubres, pudiendo ordenar respecto de estos últimos su remoción si no cumplían las condiciones impuestas para su ejercicio, o si este se hiciere incompatible con la salud pública, la vigilancia del expendio de substancias alimenticias, prohibiendo la venta de las que por su calidad o condiciones fueran perjudiciales a la salud pública, la conservación y reglamentación de cementerios, el aseo y mejora de los mercados, mataderos y corrales, y la adopción de las medidas y disposiciones tendientes a evitar las epidemias, disminuir sus estragos, investigar y remover las causas que las produjeran o sostuvieran y las que concurrieran a asegurar la salud y bienestar de la población.

4 Cfme. Art. 48 , inc. $1^{\circ}$ a $9^{\circ}$ de la Ley $N^{\circ} 1260$ (Congreso de la Nación Argentina, 1882, p. 1026). 
En cuanto a las competencias del Concejo referidas a la beneficencia y moralidad pública ${ }^{5}$, se destacó lo relacionado con la fundación y reglamentación de las casas de corrección y de trabajo, los asilos para pobres imposibilitados de trabajar, los asilos y colegios de huérfanos, las casas de expósitos y hospicios de dementes y, principalmente, la creación, dirección y administración de hospitales y establecimientos de caridad.

Varias actividades que de un modo $\mathrm{u}$ otro afectaban la higiene, fueron obligadas a contribuir al erario municipal, declarándose entre otros impuestos y rentas municipales: el impuesto de abasto, el de extracción de arena, resaca y cascajo; el derecho de piso en los mercados de frutos del país; el impuesto y arrendamiento de los mercados de abasto, el impuesto de alumbrado, limpieza y barrido; las patentes sobre mercados particulares, tranvías, carruajes y vehículos en general, perros y establecimientos de máquinas a vapor; el producto de la conducción de cadáveres, de la venta y reparto de sepulturas; de las hospitalidades, de las casas de dementes y de la venta de los residuos de basuras. ${ }^{6}$

Con la sanción de la Ley Orgánica Municipal, a la que se sumó el inicio de la primera Intendencia de Buenos Aires de Torcuato de Alvear, la institucionalización de la Asistencia Pública (1883) y la Administración Sanitaria (1892), se amplió la capacidad de gestión públi-

5 Cfme. Art. 50, inc. $1^{\circ}$ y $2^{\circ}$ de la Ley $N^{\circ} 1260$ (Congreso de la Nación Argentina, 1882, p. 1026).

6 Cfme. Art. 65, inc. $1^{\circ}$ a $5^{\circ}, 7^{\circ}$ y 12 a 14 de la Ley $N^{\circ} 1260$ (Congreso de la Nación Argentina, 1882, p. 1029). ca, intentando dar respuestas higiénicas a ciertas realidades que requerían una eminente intervención. Según Michael Foucault, con el ejercicio de la medicina en el ámbito urbano surge la noción de salubridad “(...) la base material y social capaz de asegurar la mejor salud posible a los individuos (...) con ella surge el concepto de higiene pública como la técnica de control y de modificación de los elementos del medio que pueden favorecer o perjudicar la salud" ([1980] 1996, p. 100).

En materia de salubridad, si bien Buenos Aires fue exhibiendo sus progresos urbanos, no faltaron comentarios, como los del médico José Penna, que dieron cuenta de que esa realidad resultaba solo aparente, y que la prestación del servicio higiénico por parte de la ciudad era incompleta desde las prácticas de saneamiento.

(...) fundada sobre un suelo de condiciones geológicas y topográficas favorables, se resintió desde muy temprano de la desidia y abandono de sus primeros pobladores que lo infectaron, arrojando en sus capas más superficiales, los residuos (...) Y si bien es cierto que (...) han de haber operado en él cambios favorables, ateniendo el grado de insalubridad, no podría dejarse de admitir que, á pesar de esas circunstancias, existen todavía en el suelo focos de infección capaces de entrar en actividad el día en que un concurso de causas favorables se reúnan y establezcan vías de acceso que 
franqueen su aislamiento. La supervivencia de ciertos gérmenes patógenos autoriza a desconfiar (...) como la aparición de la fiebre tifoidea (...) (Penna \& Madero, 1910, p. 52).

En lo que respecta a la Asistencia Pública, esta tuvo a su cargo la creación de servicios auxiliares como: 1) la asistencia domiciliaria o seccional, con el objeto de beneficiar y promover la privacidad y familiaridad de los enfermos leves o crónicos, ampliando, a su vez, la disponibilidad de camas y la reducción del gasto por internación; 2) la asistencia hospitalaria y 3) la de los consultorios externos. Estos servicios complementaron las funciones que se le habían incorporado a la Asistencia Pública como los de profilaxis, Administración de la Vacuna y Casa de Aislamiento para las enfermedades infectocontagiosas. La Administración Sanitaria, como sección constitutiva de la institución anterior, se hizo cargo, en cambio, de las atribuciones referidas a todos los factores que pudiesen perturbar la salud pública del municipio; por consiguiente era de su incumbencia el "investigar, por los medios á (sic) su alcance, las causas, el origen y la propagación de las enfermedades que existan en el municipio, y averiguar hasta donde dependen estas enfermedades de condiciones que se puedan remover ó (sic) mitigar", como así también, "informarse por medio de la inspección sistemática, respecto de las condiciones perjudiciales á (sic) la salud pública que existan en el municipio y proponer las medidas que sea ne- cesario tomar para mejorar el estado higiénico de la comunidad ó (sic) combatir las causas que puedan perjudicar á (sic) ésta. (Penna \& Madero, 1910, p. 42). Dentro de sus funciones programadas cabía la obligación de visitar los casos particulares en los cuales se produjeran enfermedades infectocontagiosas o epidémicas, asistir a la vigilia de aquellos establecimientos insalubres, a los lugares con presencia de animales o sustancias que puedan perjudicar la salud de la población. Asimismo tenía a su cargo el seguimiento y la elaboración estadística de las defunciones por enfermedad y las medidas implementadas, como también la dirección de las Comisiones de Higiene Parroquial y las dependencias como la "Casa de Aislamiento" (hoy Hospital de Infecciosas "Doctor Francisco Muñiz”), Desinfección, Dispensario de Salubridad, los Laboratorios de Bacteriología y de Vacuna Antirrábica, Tren Central de Ambulancias, y las inspecciones comerciales como la de los mercados, abasto, tambos y carnicerías, a fin de procurar la mejor calidad y condición de los productos alimenticios. La Administración debía ejercitar dentro de sus posibilidades todas aquellas prácticas de saneamiento y de profilaxis para promulgar la conservación de la salud y la prolongación de la vida de los ciudadanos, limitando la proliferación de las enfermedades endémicas y el progreso de las epidémicas.

A partir de este contexto normativo, quedó estructurado el régimen municipal y se enfatizó la aplicación de medidas preventivas de higiene, a cuestiones 
que se hacían evidentes, como la expresada en la Memoria del Presidente de la Comisión Municipal al Concejo:

¿En qué condiciones de salubridad se halla nuestro municipio? ¿Son ellas ventajosas? $\mathrm{Si}$ hemos de estar á (sic) las reglas que como indispensables señalan los modernos higienistas, nuestra deficiencia es mucha y mucho habrá que hacer para alejarla de los peligros inherentes á (sic) todas las que se encuentran en su estado. No tenemos calles anchas ni bien aireadas, ni plazas y paseos públicos cómodos y en número que se relacione con la población; los establecimientos insalubres pueblan su centro cuando debieran encontrarse completamente alejados de él (1882, p. 324).

\section{Hospitales en la ciudad higiénica}

Cuidar la ciudad implicaba primordialmente, conservar la salud de sus pobladores y prevenirlos de las enfermedades transmisibles. Esta preocupación sostenida por el grado de insalubridad y de infección que exhibía Buenos Aires, determinó la aplicación pública de la higiene como práctica para la prescripción de reglas profilácticas que organizaran y velaran el adecuado desenvolvimiento en el ámbito urbano. Si hacemos referencia al sistema hospitalario presente en la organización administrativa de la ciudad de finales del siglo XIX, conformado por nosocomios destinados a construir ámbitos higiénicos para el diagnóstico y tratamiento de los enfermos, debemos hacer mención de la situación con la cual se encontró el primer director general de la Asistencia Pública, doctor José María Ramos Mejía, al asumir su cargo el 9 de febrero de 1883. La capital solo contaba con la disponibilidad prestataria de cinco establecimientos médicos que dependían directamente de ella, entre los que se encontraban, según Penna y Madero (1910): Hospicio de las Mercedes (320 enfermos), Hospital de Buenos Aires (244 enfermos), Antiguo Hospital General de Hombres (173 enfermos), Casa de Aislamiento (80 enfermos) y Hospital San Roque (36 enfermos). Un mes más tarde, el Hospital de Buenos Aires, cuyo servicio se orientó a la medicina clínica, pasó a formar parte de la jurisdicción nacional y el de Hombres fue clausurado definitivamente el 21 de noviembre del mismo año, trasladando los servicios de este, al Hospicio de las Mercedes y al Hospital San Roque, que había sido inaugurado el 12 de agosto de 1883 con nuevas instalaciones para la prestación del servicio médico. En la búsqueda de una solución al hacinamiento en los hospitales municipales por presentar camas permanentemente ocupadas para la atención de enfermos crónicos, se instaló, en octubre de 1885 , el Hospital de Crónicos o Casa de las Hermanas en el antiguo Departamento de Hermanas que había quedado en el Hospital General de Hombres, si bien por razones presupuestarias, sus servicios quedaron clausurados en enero 
de $892^{7}$, la necesidad de adecuar espacios específicos para el servicio de los convalecientes se sumó a los primeros lineamientos de una renovación hospitalaria que requería nuevas estructuras y readecuación de viejas formas. Ante esta situación, la inmediatez para reorganizar y ampliar el sistema hospitalario se hacía cada vez más urgido; y como señalara el doctor Ramos Mejía, “(...) tan indispensable en la organización administrativa de una ciudad culta, que sabe valorar la importancia real y positiva de sus elementos componentes y el significado que en la ecuación de la vida de los pueblos tiene el hombre sano y lo que representa en su progreso la atenuación de la morbilidad y la reducción de su mortalidad". (Penna \& Madero, 1910, p. 135)

A partir del Censo General de Población de 1904 (Municipalidad de la Ciudad de Buenos Aires, 1906), la ciudad de Buenos Aires contaba con un total de 944.742 habitantes, sin considerar los 6.149 habitantes fluviales, según las observaciones de Penna y Madero (1910). La ciudad se encontraba dividida en veinte secciones, y más de la mitad de su población total $(51,23 \%)$, residía en siete secciones, a saber: $3(8,98 \%), 19$ $(7,53 \%), 8(7,14 \%), 13(7,11 \%), 9$ $(6,98 \%), 18$ y $12(6,75 \%$ cada una).

7 En el año 1906 se inauguraron las instalaciones del nuevo Hospital Intendente Dr. Antonio Crespo, emplazado en un terreno análogo al anterior de Crónicos. A partir de esta situación, se trabajó sobre un proyecto dirigido a construir un hospicio-asilo para los enfermos crónicos, mendigos de ambos sexos. En 1909 se dio traslado a todos los enfermos del Hospital Crespo hacia el nuevo establecimiento denominado Hospicio Intendente Torcuato de Alvear.
De acuerdo con la clasificación de Penna y Madero (1910), con base en los datos del mismo censo, la ciudad de Buenos Aires tenía 5.981 manzanas habitadas, de las cuales el 47,83\% (2.861) estaban infectadas, entre otras, por las siguientes enfermedades: viruela, sarampión, escarlatina, fiebre tifoidea, tuberculosis, difteria, fiebre puerperal y meningitis. Estas manzanas se encontraban principalmente ubicadas en las secciones 3,4 , $18,5,9,19,2$ y 6 , que reunían en total 1.491 manzanas, es decir, el 52,11 \% de las infectadas; y puede afirmarse que las defunciones ocurridas por enfermedades infecciosas en la Capital Federal entre 1872 y 1904 (Penna \& Madero, 1910, p. 71), se debían predominantemente a: tuberculosis, meningitis, neumonía, bronconeumonía, bronquitis, difteria y cruz, tétano y fiebre tifoidea.

Por consiguiente, la necesidad de contar con acciones preventivas ante las enfermedades trasmisibles, que ampliaran el radio de atención y prevención médica de la capital, hizo que el servicio delegado a la Asistencia Pública de la Administración de la Vacuna, se consolidara como una medida profiláctica indispensable para el cuidado de la ciudadanía. Con la vacunación antivariólica, el registro estadístico y los folletos distribuidos gratuitamente, el programa desarrolló una estructura administrativa basada en el emplazamiento de ocho oficinas seccionales de vacunación, comprendidas por dos o tres secciones del Registro Civil, ubicadas en la zona céntrica de cada área asignada. Este servicio público se complementó por 
internmedio de comisiones de vacunación a domicilio, a fin de extender la inoculación a un número mayor de habitantes, las que visitaban las parcelas en cada manzana detectando los focos contagiosos y las anomalías: ausencia en el domicilio, resistencia a ser vacunado o no disponer el comprobante de aplicación. Estas comisiones se diferenciaron en "sucias" cuando practicaban la vacunación en sitios infectados y "limpias" cuando lo hacían en casos con probabilidad de contagio. Bajo la Ley $\mathrm{N}^{\circ} 4202$ (Congreso de la Nación Argentina, 27 de agosto, 1903), la obligatoriedad de la vacunación y revacunación quedó establecida para los niños de 0 a 1 año; adultos que prestaban servicio activo en el Ejército y la Armada, estudiantes de colegios militares, inmigrantes, huérfanos, inválidos, mendigos, enfermos ingresados en los hospitales y toda persona dedicada a la venta, manipulación y reparto de sustancias alimenticias. Esta preocupación por las tasas de mortalidad en el ámbito urbano, no tuvo correspondencia inmediata en resolver la habilitación de nuevos establecimientos al servicio de la comunidad. Si bien la Asistencia Pública de la Capital desde su formación pudo desarrollar algunos servicios básicos para el bienestar de la población, resultó muy limitada su actuación para instalar cambios sustanciales en el funcionamiento hospitalario y adecuarlo a las necesidades sociales y el crecimiento demográfico de la ciudad, en materia de mantenimiento, reformulación, ampliación y construcción de nuevos establecimientos, siguiendo los lineamientos higiénicos que se requerían para la conformación del espacio hospitalario.

Separado de la dirección el doctor Ramos Mejía, el 2 de marzo de 1887, y nombrado el nuevo director, doctor José María Astigueta, se constituyó una comisión inspectora para diagnosticar el estado de los hospitales y demás establecimientos de la Asistencia Pública. El informe arrojó, de manera no casual y novedosa, la urgencia por atender los inconvenientes que se venían manifestando en el servicio sanitario desde la institucionalización de la Asistencia Pública, y la necesidad de que la municipalidad no dejara librada la situación presupuestaria a los donativos y a las sociedades de beneficencia para su normal funcionamiento. De las observaciones tajantes que se elevaron con respecto al estado de los establecimientos que prestaban servicio hasta ese momento, los informantes concluyeron que los Hospitales San Roque, de Crónicos o Casa de las Hermanas y la Casa de Aislamiento no podían continuar su labor en esos lugares por no responder a los principios higiénicos que se requerían para el emplazamiento de estos nosocomios.

A partir de este informe se generaron idas y vueltas en la dirección de la Asistencia Pública y en el ámbito político de la ciudad. Lo cierto es que se implementaron nuevos servicios que resultaron de relevancia y con la restitución del doctor Ramos Mejía como director de la Asistencia Pública, se creó un nuevo servicio de Salas de Urgencia para la atención inmediata de enfermos graves y accidentados, Registro de Pobres, Es- 
cuela de Enfermeros, Laboratorio Bacteriológico, Instituto Antirrábico, y se mantuvo la disponibilidad de concursos para la cobertura de puestos técnicos. Según Penna y Medero (1910), en la dirección del doctor José María Astigueta, el 22 de abril de 1889, se inauguró el Hospital de Inválidos, Mixto Inválidos -finalmente conocido como Rawson-, la Inspección Médica de la Prostitución -posteriormente Dispensario de Salubridad-, incorporándose estos organismos y servicios a la jurisdicción municipal.

En materia de construcción hospitalaria, bajo la dirección del doctor Juan Bautista Señorans, se inició la obra, en 1894, del nuevo Hospital de Asilamiento (Casa de Aislamiento), luego Hospital Muñiz y del Hospital Belgrano, luego Hospital Doctor Pirovano. Años más tarde, siendo director de la Asistencia Pública el doctor Telémaco Susini, comenzó la construcción del edificio de la Casa Central de la Asistencia Pública, emplazado en el lugar que ocupara el antiguo Hospital de Mujeres, la construcción del Hospital de Flores, luego Doctor Álvarez, el pabellón de cirugía y obstetricia del Hospital San Roque, los pabellones del Hospital del Norte, el proyecto de construcción de un hospital para tuberculosos, luego Sanatorio Tornú, Hospital seccional de la Boca, luego Argerich, los cuales resultaron ser la base edilicia primordial de la ampliación del servicio hospitalario de las próximas décadas.

Transcurridos más de veinte años, la ciudad de Buenos Aires presentaba otra realidad de su infraestructura médica edilicia. Haciendo referencia al cuadro presentado por Penna y Madero (1910, p. 250-251), la Administración Sanitaria y Asistencia Pública de la ciudad de Buenos Aires contaba con los servicios médicos de la capital, distribuidos por la jurisdicción de los establecimientos y el servicio interno de salas y consultorios externos que disponían. Entre los establecimientos se encontraban los de la Asistencia Pública, los Nacionales, los pertenecientes a la Sociedad de Beneficencia, al Patronato de la Infancia, aquellos hospitales de origen extranjero y los particulares, que sumaban un total de 59 establecimientos de asistencia médica (entre hospitales, sanatorios, casas -de socorro, expósitos, huérfanas-, maternidad, enfermerías y consultorios, escuela de arte y oficios, internados, e institutos). En relación con la conformación de la Asistencia Pública en el sistema hospitalario, aparte de fiscalizar la asistencia médica de los demás establecimientos, prestaba un servicio público en clínica médica y quirúrgica de hombres y mujeres, ginecología, enfermedades nerviosas, genitourinarias, dermatología y venéreas, otorrinolaringología, oftalmología, enfermedades de niños, infectocontagiosas, de tuberculosos y crónicas. Su estructura edilicia estaba formada por: una oficina o casa central de la Asistencia Pública (donde funcionaban la dirección, la administración sanitaria, el servicio médico central y de primeros auxilios), ocho hospitales donde se desempeñaban los consultorios o dispensarios externos (San Roque, Álvarez, Fernández, Rawson, Muñiz, Crespo, Pirovano y Argerich), y dos en 
construcción (Durand y Piñero); un sanatorio (Tornú) (Figura 3); ocho casas de socorro como pequeños centros de asistencia médica pero con iguales funciones que un hospital, dos asilos (uno en construcción), un laboratorio central de bacteriología y una escuela de enfermeros. Bajo esta nueva estructura hospitalaria de 1910, y recurriendo a los datos deducidos del Censo General de Población de 1904, las cinco secciones de mayor extensión de la ciudad $(1,15$, 16,17 y 5 ) reunían en conjunto el 70,59 $\%$ de la superficie total de la ciudad, a la vez que concentraban el 11,27\% de la población y el 21,25\% de las manzanas infectadas (608). Vale destacar que en esa amplia zona, el servicio hospitalario de la Asistencia Pública contaría con cuatro establecimientos: Álvarez, Pirovano, Piñero y el sanatorio Tornú.

Figura 3. Esquema de ubicación de hospitales de la Capital.

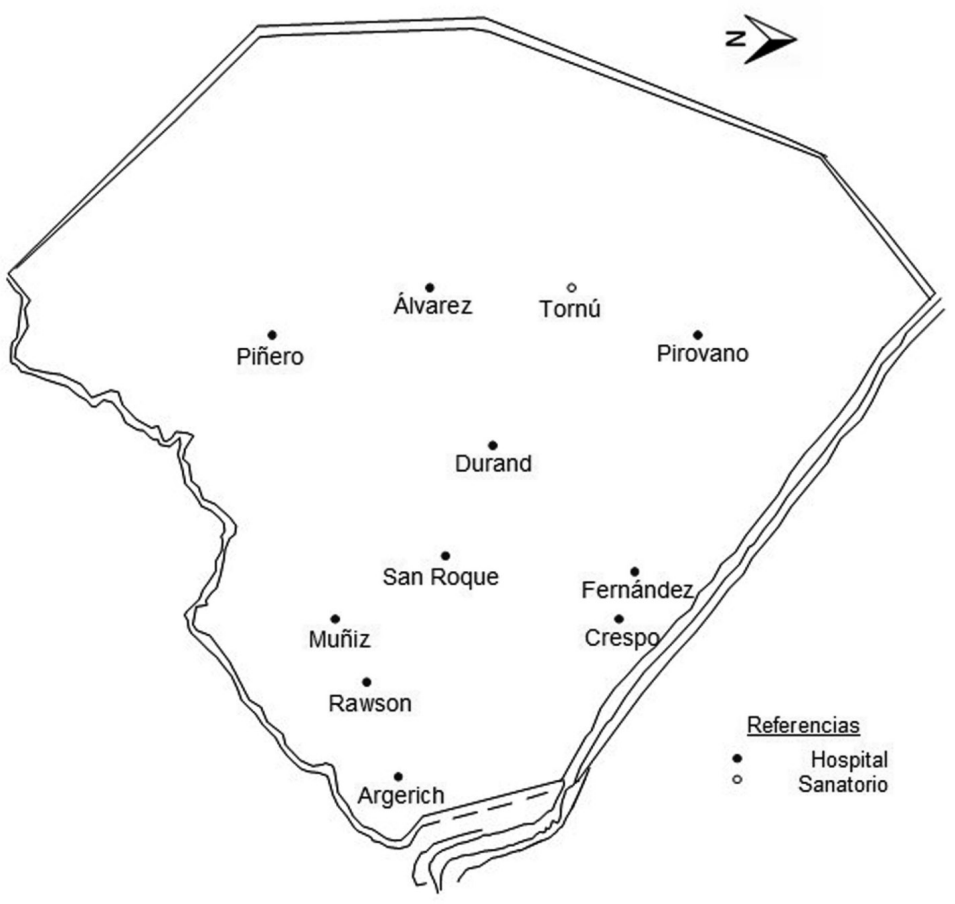

Fuente: elaboración propia.

Con el higienismo se incorporó la idea de "verde" como instrumento sanador en un modelo de ciudad sana, bajo una noción organicista de la trama urbana, en la cual se consideraba a la ciudad como un "organismo vivo" que respira- ba a través de la vegetación, promoviendo la calidad de vida y bienestar de sus habitantes. Esta concepción primó en la planificación de los espacios públicos como en el arbolado de aceras de calles $\mathrm{y}$ avenidas, jardines, plazas y parques 
(Figuras 4 y 5), y en la incorporación de tareas especializadas en jardinería y producción en el "criadero de plantas" para proveer diversas especies vegetales a sitios existentes y proyectados de la ciudad. Estas intervenciones paisajísticas se vieron potenciadas en las gestiones consecutivas de la Dirección de Parques y Paseos de la Municipalidad de la Capital, del arquitecto Charles Thays (1891-1914), y del ingeniero agrónomo Benito Carrasco (1914-1918), quienes trazaron los ejes rectores para la gestión de los trabajos realizados en el espacio público, mediante un adecuado tratamiento de las áreas verdes, que no solo contemplaron su importancia estética, como diría Carrasco (1924), sino también la higiene, solaz y expansión de la población. Este concepto de paisaje urbano se basaba en la jerarquía y relevancia de las áreas verdes, las que resultaban primordiales para mostrar el progreso y la "civilización" de una ciudad. Paisajísticamente, Buenos Aires mostraba otra morfología que, según Armus (2007), se tradujo en tres instancias muy marcadas en el proceso urbano de finales del siglo XIX y principios del $\mathrm{XX}$, en las cuales esta ciudad verde describió su funcionalidad como pulmón, ámbito de civilización y recreación.

Figura 4. Plaza de Mayo a finales del siglo XIX.

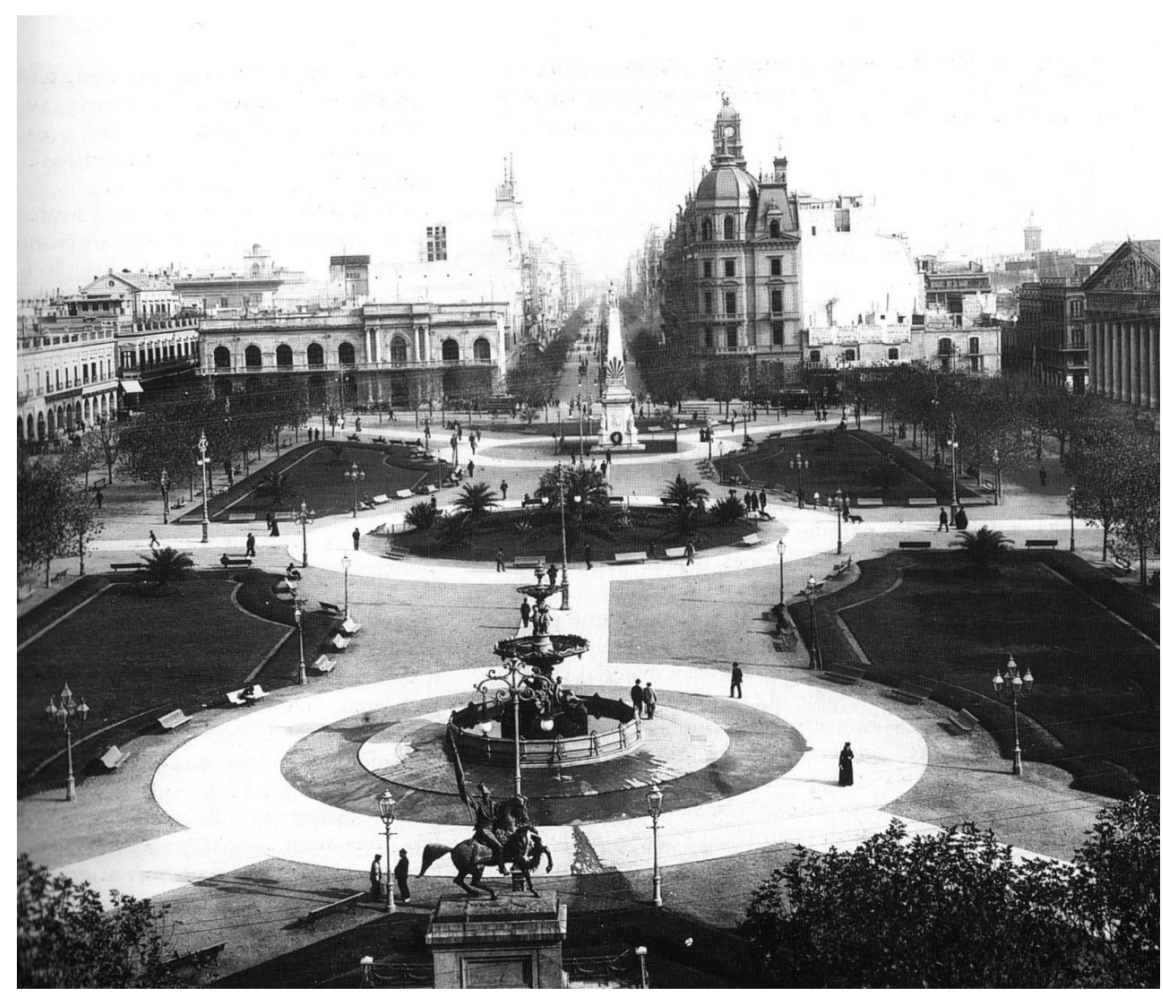

Fuente: Archivo General de la Nación. 
Figura 5. Parque Garibaldi en Palermo (s.f.).

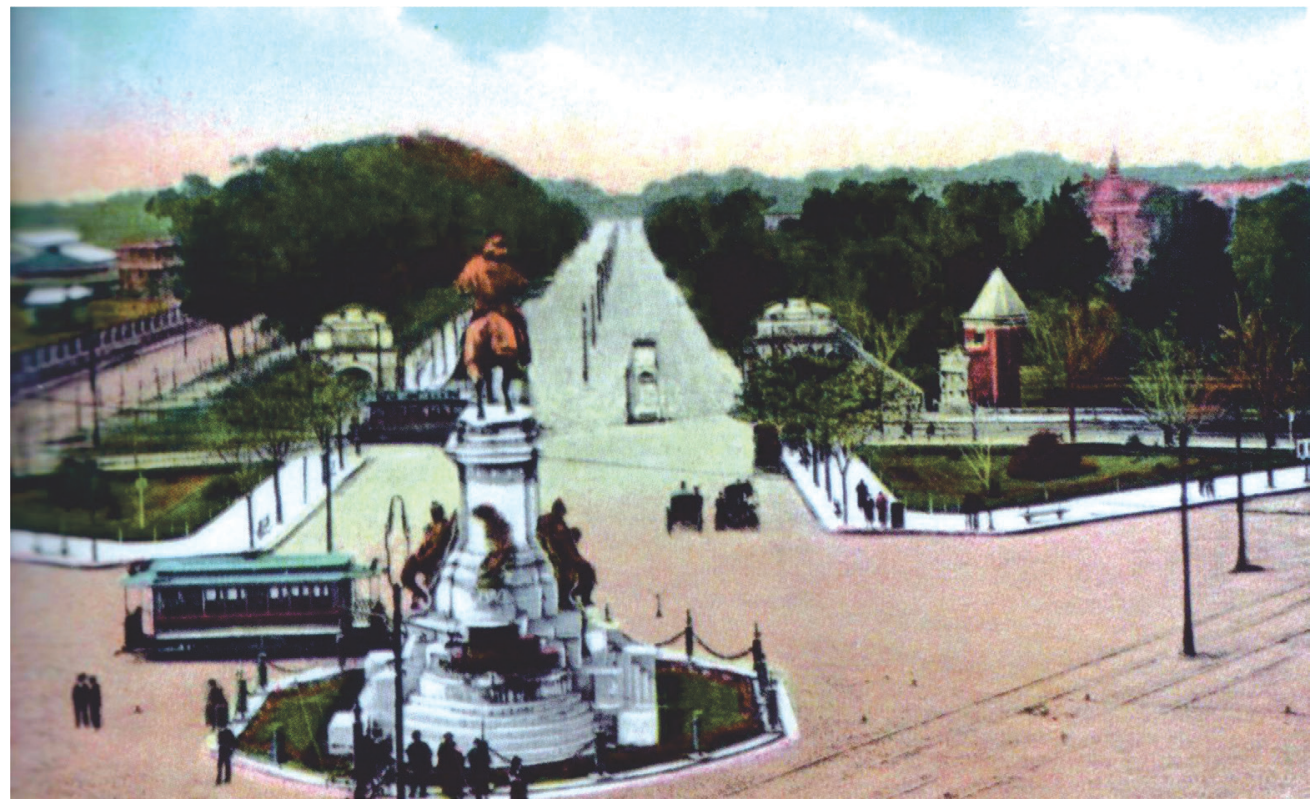

Fuente: Gobierno de la ciudad de Buenos Aires (2005)

En este marco urbanístico se desarrollaron programas para la implementación del servicio y la calidad del agua potable, el tratamiento e incineración de los residuos, el saneamiento cloacal, las inspecciones sanitarias de los mataderos, cementerios, sumándose a la habilitación de hospitales y la construcción de establecimientos sanitarios ya mencionadas. En ese modelo de ciudad higiénica y de nuevos criterios paisajísticos ligados a la gestación y valorización de los espacios verdes públicos, basado en el pensamiento epidemiológico, se instauró un discurso político y un saber científico, institucionalizando al hospital como medida indispensable de protección higiénica y disciplinar. Se configuró un paisaje hospitalario que respondió a una norma de organización sanitaria, en la cual cada hospital estaría compuesto por un sistema de pabellones aislados y a la vez vinculados entre sí, por áreas verdes perimetrales como piezas, articuladas y constituyentes, de un concepto de conjunto hospitalario, rodeados externamente por un muro divisorio como límite entre lo sano y lo insano de la ciudad.

\section{Paisaje hospitalario}

Este paisaje de la Buenos Aires higiénica con sus dinámicas urbanas y su nueva organización espacial fue modelando lo hospitalario; complejizando y diversificando la vida en sociedad y de las formas paisajísticas de ver ciudad. Este paisaje, "como el dominio de lo visible, 
lo que la vista abarca. No sólo está formado por volúmenes, sino también por colores, movimientos, olores, sonidos, etc." (Santos, 1996, p. 59). Asimismo, en el decir del autor, se fue organizando por niveles circulatorios, constructivos y de distribución, en un proceso que trasparentó una lectura de escrituras superpuestas con edades diferentes, como una herencia de muchos momentos pasados en los que se yuxtaponen formas heterogéneas de diversas maneras de producir y construir el espacio urbano. En una ciudad en la cual la higiene prevalecía como práctica pública para evitar la propagación de las enfermedades trasmisibles, se estableció un borde entre lo sano y lo enfermo. Este borde materializaría la decisión de aislar todo aquello que comprometiera la sanidad pública, lo cual conllevó a la división de la ciudad en un "adentro" y un "afuera": por un lado, el área urbana (central) de características fundacionales, residenciales, comerciales y de paseo y, por el otro, los suburbios (la periferia), donde se instalaron las industrias, mataderos, basurales, cementerios, cárceles y hospitales; actividades y servicios que fueron expulsados por "sucios" y "peligrosos" hacia los márgenes, modelando un particular paisaje urbano como expresión del ordenamiento geográfico. A partir del acto de aislar, se apartaba lo contaminado de lo higiénico, sustrayendo lo infecto de lo puro y separando de la cotidianeidad los cuerpos y elementos dudosos que se encontraban en el medio.

En esta organización espacial quedó delineada la idea de paisaje hospitalario, con sus pares dialécticos entre lo sano/ enfermo, centro/periferia, limpio/sucio, interno/externo higiénico/infecto, como contradicciones geográficas; y en esa misma imagen quedaban aislados los "anormales", al decir de Michel Foucault ([1974-75] 2000): locos, presos y enfermos infectocontagiosos; como también aquellas mujeres que ejercían la prostitución y requerían un estricto control, que mediante la "(...) secuestración de las enfermas en el Hospital "J. A. Fernández" (Penna \& Madero, 1910, p. 45), se llevaban a cabo los tratamientos de las enfermedades venéreas contraídas. Este aislar implicaba contar con sitios especiales que sirviesen como instrumentos de contención y terapéuticos para el cumplimiento de las políticas higiénicas. Estos lugares o establecimientos públicos, como lo eran los hospitales, debían emplazarse lo más lejos posible del centro urbano de la ciudad, y garantizar la especialización en el cuidado de los enfermos, y el resguardo estricto por aquellas enfermedades infecciosas que pudiesen presentar signos de propagación y consecuentemente peligros de contagio a la población. En este marco, la institución hospitalaria debía asegurar un correcto funcionamiento acorde a las circunstancias que se habían planteado. Ese alejamiento no solo tuvo una correspondencia entre el centro y la periferia, sino que se vio instrumentado en la propia funcionalidad interna del hospital. Funcionalidad contenida espacialmente a partir de polígonos cercados que articularon lo construido y lo verde en su interior, plasmando la diferencia con la 
trama reticular de Buenos Aires y los espacios verdes abiertos que urbanizaban el suelo (Figura 6). A su vez, en el mismo interior del hospital se encontrarían alejados entre sí los convalecientes de los enfermos comunes, los infectados de su entorno familiar y del resto de los hospitalizados, los vacunados de los no inmunes, como así también, el personal que prestaba un servicio público, responsable de custodiar la efectividad de las prácticas higiénicas mediante el encierro.

Figura 6. Plano definitivo del Hospital Muñiz exhibiendo la distribución de los pabellones y los jardines que lo conforman.

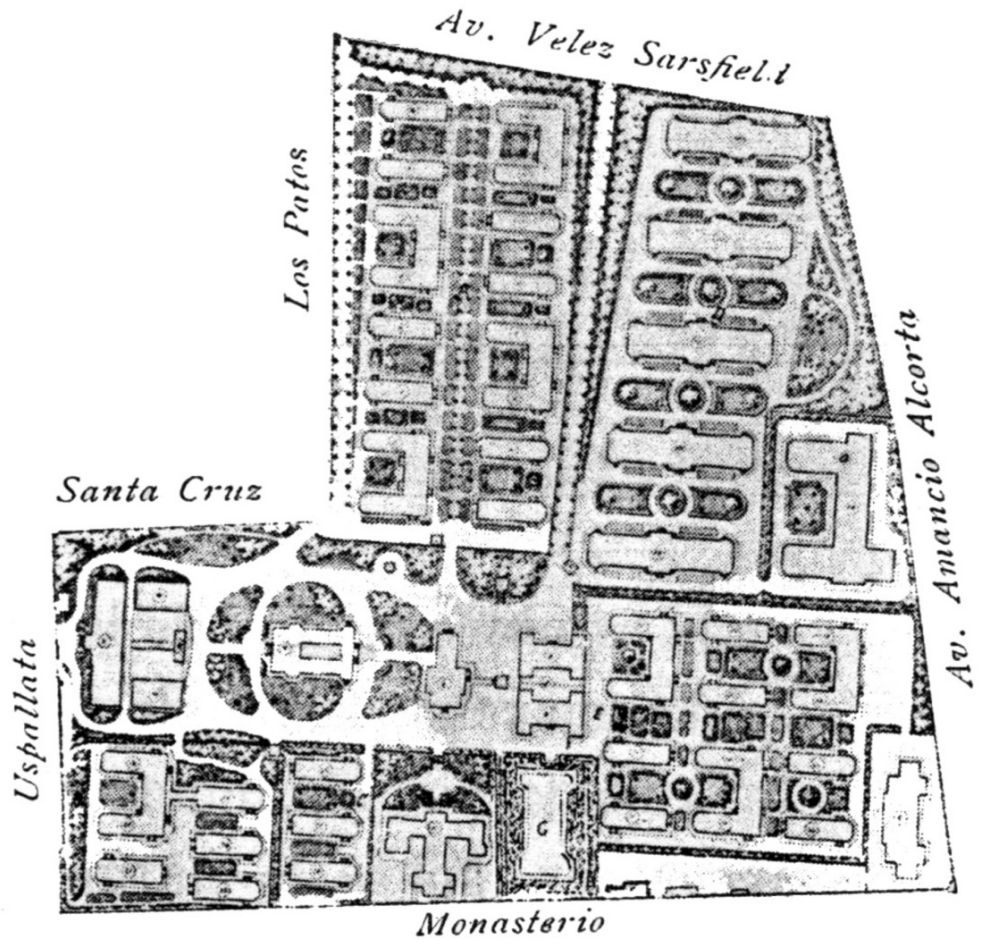

Fuente: Penna y Madero (1910, p. 327).

La erradicación de lo antihigiénico, hizo ajustar las prácticas higienistas en torno al "aislamiento" como medida profiláctica directriz, en la prevención y terapéutica de las enfermedades en el ámbito urbano, saneando y desinfectando todo aquello que resultara infecto, me- diante el alejamiento y la destrucción de cualquier objeto y sitio que pudiese poner en evidencia las falencias sanitarias de un sistema en permanente vigilia y control social. Un sistema que gobernaba mediante el control, ejerciendo el poder de la "disciplina", en los términos 
de Michel Foucault ([1976] 2000), que funcionaba con el hecho de ordenar y encauzar conductas, garantizando multiplicar ese accionar de los individuos de la manera más efectiva y extensivamente posible. Ese ejercicio disciplinario suponía un dispositivo de coacción que "normalizara" el mismísimo sistema hospitalario, capaz de hacer funcionar la reglamentación sobre la higiene pública que había sido sancionada y que requería obligatoriamente generalizar los actos que implicaban la denuncia-inspección-sanción-examen de las fuentes que daban origen a la afección y comprometían el sistema profiláctico sanitario que se había instalado. Este diseño espacial de panoptismo disciplinario promovido desde el sistema hospitalario conjugó “(...) una estricta división espacial (...) espacio recortado, inmóvil, petrificado. Cada cual está pegado a su puesto, Y si se mueve, le va en ello la vida, contagio o castigo" (Foucault, [1975] 2000, p. 199), que planeaba el de una conducta de registro permanente; diferenciando y marcando el desorden mediante la penetración de la ley. Para el autor, las enfermedades epidémicas formaban parte de ese desorden, leyéndose la obsesión por el contagio detrás de los dispositivos disciplinarios como lo era el hospital. "Pero cuando la enfermedad es de marcha prolongada como sucede con las infecciones crónicas, entonces el aislamiento pierde toda su importancia, en vista de la imposibilidad de poderlo cumplir regularmente. Nadie, por más convencido que esté de lo peligroso de la enfermedad que lo afecta, se conforma con agregar á (sic) su mal incurable, la suerte del prisionero" (Penna \& Madero, 1910, p. 110).

Si bien la custodia de la ciudad era considerada prioritaria en la agenda pública, para lo cual se sancionaron y modificaron ordenanzas para hacer más efectiva la gestión, no lograría abarcar toda la extensión, a pesar de los instrumentos y medidas implementados para el control. “(...) La Administración Sanitaria jamás podrá conocer la situación sanitaria de los habitantes de esta ciudad, (...) ignora la proporcionalidad relativa entre esta mortalidad y la morbilidad que le ha dado origen, á (sic) la cual sólo le es permitido remontarse por aproximación, (...) la proporción alcanzada en los hospitales. (...)" (Penna \& Madero, 1910, p. 104). Asimismo, la generalización del aislamiento como recurso defensivo ante las enfermedades trasmisibles, tuvo sus diferencias de aplicación en cuanto a las dolencias que debía atender. Es decir, como mencionaron los médicos José Penna y Horacio Madero (1910), el aislar se hizo aplicable en los casos de escarlatina y difteria, por la facilidad en obtener un diagnóstico precoz del paciente; pero no lo era eficaz, el alejar aquellos casos como el sarampión y la coqueluche, dado que al ser enfermedades que no presentaban síntomas iniciales adversos, a lo que se agregaba el no saber de su manifestación como padecimiento, los enfermos circulaban propagando los gérmenes del contagio y la instancia de aislar no llegaba a tiempo. En igual medida resultaba el hecho de reducir el tratamiento por peste bubónica y pústula maligna con el 
solo hecho de alejar a los enfermos, si no se tenían en cuenta las causas que la ciudad propiciaba por la carencia de tratamientos que controlaran los focos contaminantes por roedores y animales infectados, que hacían del aislamiento un recurso anómalo para la cura y prevención sanitaria. Y en la organización de los espacios urbanos primó el emplazamiento de estos hospitales contenidos, en los cuales la forma preventiva era construir un ámbito higiénico, $y$, tal como señala Michel Foucault: "el orden arquitectónico, (...) impone en el suelo sus reglas y su geometría a los hombres disciplinados" ([1975] 2000, p. 193). En este sentido, plasmado en la generalidad, el hospital fue concebido bajo criterios higienistas en los cuales se evidenció la acción benefactora de la luz natural, los ambientes ventilados y la altura de los edificios, que se vieron favorecidos por la distribución aislada de los pabellones y del uso adecuado de la vegetación como manto circundante de saneamiento exterior (Figuras 7 y 8). "Los jardines llenos de árboles que aíslan y separan los distintos pabellones, contribuyen á (sic) dar al hospital, un aspecto alegre que contrasta con la idea que en general se tiene de estos establecimientos, y al mismo tiempo proporcionan á (sic) los convalecientes sitios agradables donde pueden reposar durante el día, respirando un aire más puro y vivificante que el de las salas" (Penna \& Madero, 1910, p. 274).

Figura 7. Hospital San Roque (s.f.).

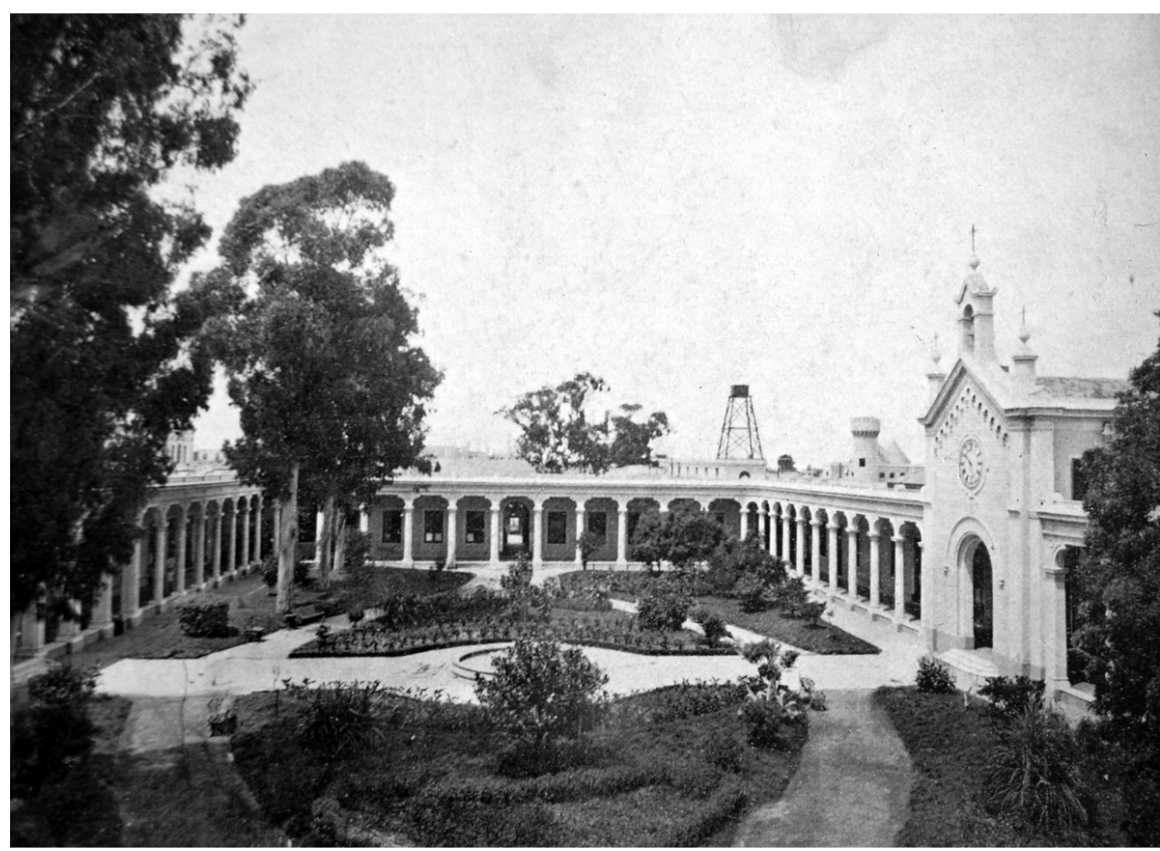

Fuente: Archivo General de la Nación 
Figura 8. Hospital Pirovano (s.f.).

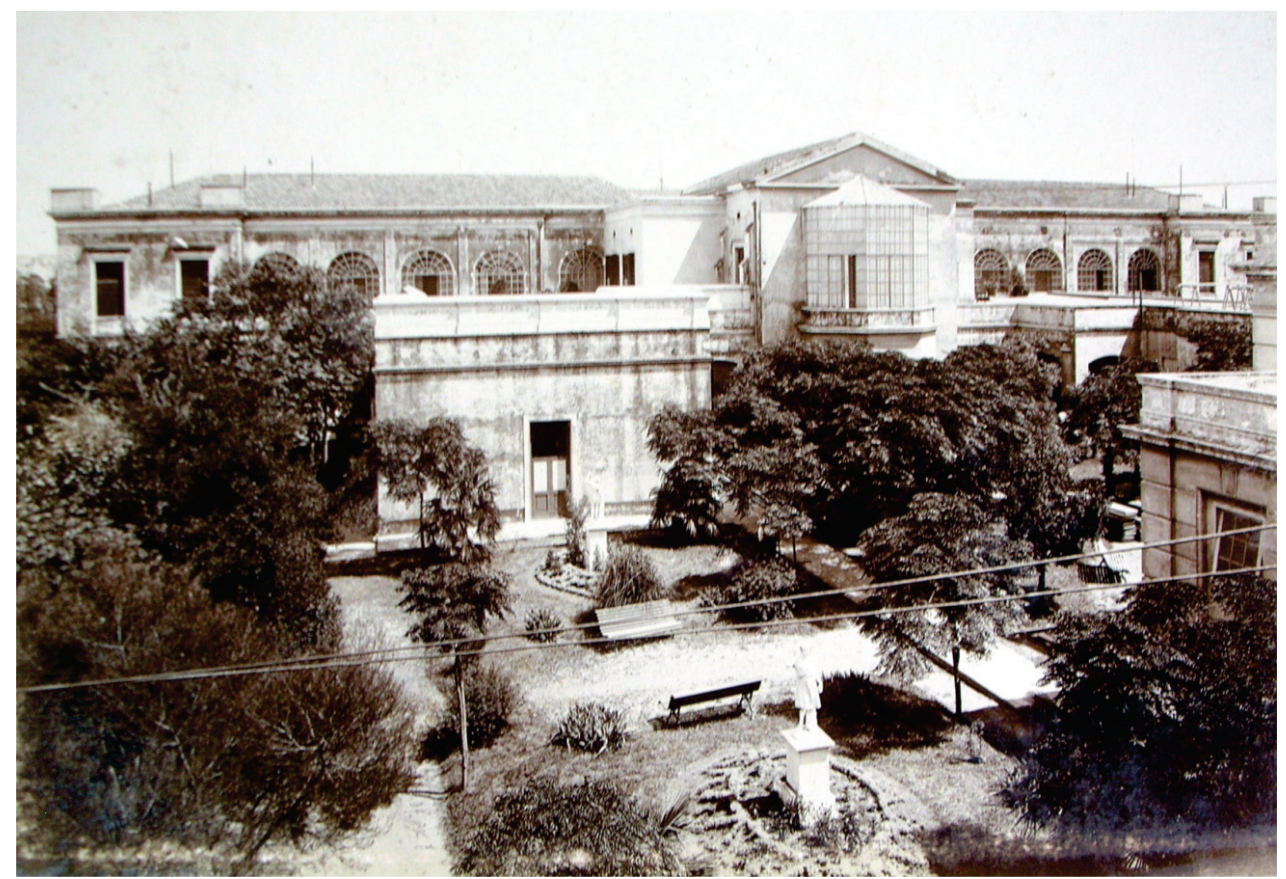

Fuente: Archivo General de la Nación (der.).

En este contexto se fueron articulando esos espacios verdes a modo de jardines en los hospitales, sujetos a la idea de materializar la separación entre los pabellones, pero a la vez comunicando a todo un conjunto sanitario. En esta noción de espacio verde hospitalario se hizo hincapié en las especies arbóreas dispuestas como masas envolventes y coberturas de césped, como elementos compositivos fundamentales para el tratamiento exterior. Estos espacios ajardinados se incorporaron como módulos repetitivos, incluidos en un dispositivo mayor como lo era la institución hospitalaria, modelando un diseño espacial que determinó, no solo el beneficio que estos espacios verdes reunían para el ambiente urbano, cada más acelerado e industrial, sino que además, normalizó el modelo de hospital con jardines como recursos hospitalarios de aislamiento, decoración y terapéutico, que en su devenir histórico hasta el presente, reflejó nuevas representaciones en el marco de las propuestas sanitarias que se instalaron en la complejidad de la sociedad actual.

\section{Conclusiones}

Los procesos de reorganización de la ciudad de Buenos Aires transparentaron cuestiones urbanas referidas específicamente a la higiene y a la salud preventiva de la población que comprometieron la proyección de políticas públicas ajusta- 
bles a las situaciones que se suscitaban. En este marco, el servicio sanitario de la ciudad mostró su debilidad para hacer frente a las realidades más urgentes que requerían la implementación y adecuación de nuevos servicios médicos. Ante las cifras alarmantes de infección en las secciones de la ciudad, el discurso médico delineó las principales acciones de intervención que alcanzaron las definiciones prioritarias que debían llevarse a cabo en los ámbitos hospitalarios. Esta articulación entre lo médico, la práctica pública de la higiene y la intervención paisajística en los hospitales de Buenos Aires, quedó sujeta con la institucionalización de Buenos Aires como Capital de la Nación y su Ley Orgánica Municipal, a partir de la cual se instrumentó un plan urbanístico, que articuló la construcción de un modelo de hospital. Este dispositivo sanitario irrumpe para hacer cumplir las normas y ordenar una gestión estatal centralizada en aminorar y erradicar la proliferación de las enfermedades endémicas y epidémicas, que ponían en peligro la salud de la comunidad. En este diseño de hospital se instrumentó la acción del "aislar", como medida de contención y diferenciación de lo que resultara enfermo y debía ser tratado. Mediante un espacio cercado disponiendo aisladamente pabellones y áreas verdes a modo de jardines, pero sirviendo a la vez, como elementos comunicantes y envolventes del conjunto, la institución hospitalaria marcó una diferenciación entre los espacios verdes públicos de parques, plazas y jardines del municipio, de su paisaje hospitalario.
En este sentido, con una mirada en el siglo XXI, estos espacios modelados tiempo atrás, aún persisten, y no solamente desde su morfología, sino como instituciones hospitalarias públicas que continúan brindando asistencia médica ininterrumpidamente desde hace más de cien años. Algunas transformadas y otras casi intactas, dan cuenta de una idea que pone en juego las diferencias en el sistema actual de salud. Lo cierto es que hoy en día, algunas realidades siguen, por lo visto, presentes: no escapamos a las situaciones de pobreza, las malas condiciones de salubridad urbana y la presencia de enfermedades trasmisibles.

Asimismo hay que destacar que a mediados del año 2008, diversos hechos pusieron en escena a dos hospitales públicos que prestan servicios a la población de buenos aires. Se hizo referencia en ese entonces al caso de los hospitales rivadavia y el muñiz; instituciones que presentaron una problemática y una característica común: la protección de sus pabellones y de su espacio verde circundante que, como conjunto, le confiere a cada hospital un valor que lo destaca en la trama de la ciudad. ${ }^{8}$

En esta nueva escena quedaron transparentados intereses disímiles y controvertidos que expusieron el debate en

8 Si bien el Hospital Rivadavia no fue objeto de análisis en el presente artículo debido a que pertenecía a la Sociedad de Beneficencia en el contexto analizado, caso contrario fue el del Hospital Muñiz, cuyo establecimiento conformó la nómina de las instituciones de la Asistencia Pública de la Capital, tal como se desarrolló precedentemente. 
el campo de lo patrimonial y la emergencia de diversos actores sociales que desencadenaron escenarios de nuevos debates políticos y sociales en torno a lo hospitalario. En este proceso se generaron iniciativas legislativas dirigidas a obtener la catalogación y protección patrimonial y ambiental de ambos establecimientos de salud, mecanismo que instaló y visibilizó la temática en la actualidad, y activó lo sancionado en 1996 por la Constitución de la ciudad de Buenos Aires. En dicha normativa, la ciudad incorpora la definición del ambiente como "patrimonio común", el derecho de toda persona "a gozar de un ambiente sano, así como el deber de preservarlo y defenderlo en provecho de las generaciones presentes y futuras" y de "recibir libremente información sobre el impacto que causan o pueden causar sobre el ambiente actividades públicas o privadas", el cese de las actividades que supongan "en forma actual o inminente un daño al ambiente" y la obligación "de recomponer" el daño ambiental ${ }^{9}$. En ese orden de ideas, establece que su política de planeamiento y gestión del ambiente urbano debe llevarse a cabo integrada a las políticas de desarrollo económico, social y cultural, contemplar su inserción en el área metropolitana e instrumentar un "proceso de ordenamiento territorial y ambiental participativo y permanente", dirigido a promover, entre otras cuestiones, "la preservación y restauración del patrimonio natural, urbanístico, arquitectónico y de la calidad visual y

9 Cfme. Art. 26 de la Constitución de la Ciudad de Buenos Aires (1996, p. 15). sonora" ${ }^{10}$; "la protección e incremento de los espacios públicos de acceso libre y gratuito" garantizando su uso común ${ }^{11}$ y la "preservación e incremento de los espacios verdes, las áreas forestadas y parquizadas, parques naturales y zonas de reserva ecológica, y la preservación de su diversidad biológica" ${ }^{12}$.

Cabe mencionar que este proceso de activación de lo hospitalario, determinó situaciones diversas de participación a lo largo de los últimos años, lo que resultó en la instalación pública de lo patrimonial en el campo de la salud, no como un hecho consumado, sino como objeto de debate por parte de la ciudadanía y de los actores involucrados, y que compromete al campo de la geografía desde una mirada orientada hacia la problematización, mediante la inclusión de situaciones locales, concibiendo el espacio geográfico desde las relaciones asimétricas de poder, cuya dinámica provoca transformaciones temporales irreversibles en la realidad, en el paisaje y en las interrelaciones entre el hombre y su entorno socialmente construido.

Hay que concluir, que el binomio salud e higiene sigue en curso, por lo cual se hace meritorio pensar la idea de ciudad desde la identificación de problemáticas sociales y reconocer la complejidad de los paisajes cotidianos, redefiniendo lo higiénico y lo verde en la construcción

10 Cfme. Art. 27, inc. 2 de la Constitución de la Ciudad de Buenos Aires (1996, p. 15).

11 Cfme. Art. 27, inc. 3 de la Constitución de la Ciudad de Buenos Aires (1996, p. 16).

12 Cfme. Art. 27, inc. 4 de la Constitución de la Ciudad de Buenos Aires (1996, p. 16). 
o readecuación del sistema hospitalario

en la planificación territorial a la vista

de las claves de este siglo. 


\section{Literatura citada}

Archivos Históricos: Archivo General de la Nación, Instituto Histórico de la Ciudad de Buenos Aires, Gobierno de la Ciudad de Buenos Aires. Ministerio de Desarrollo Urbano. Secretaría de Planeamiento. Plano de la Ciudad de Buenos Aires y Distrito Federal publicado por Pablo Ludwig. Año 1892. Recuperado de http://www. ssplan.buenosaires.gov.ar/index.php/.../mapas-antiguos

Armus, D. (2007). La ciudad impura. Salud, tuberculosis y cultura en Buenos Aires, 18701950. Buenos Aires: Edhasa.

Capel, H. (1975, febrero-mayo). La definición de lo urbano. Revista Scripta Vetera Estudios Geográficos (138-139). Recuperado de http://www.ub.es/geocrit/defin.htm

Carrasco, B. (1924) Parques y jardines. Buenos Aires: Peuser.

CEAL. (1991) Ciudad y utopía: Owen, Fourier, Garnier, Le Corbusier. Buenos Aires: Centro Editor de América Latina.

Congreso de la Nación Argentina. (1880). Ley 1029. Capitalización de la Ciudad de Buenos Aires. Recuperado de http://www.infojus.gov.ar/index. php?kk_seccion $=$ documento \&registro $=$ LEYNAC\&docid $=$ LEY $\% 252$ 0C\%2520001029\%25201880\%252009\%252020

Congreso de la Nación Argentina. (1882). Ley 1260. Versión taquigráfica $n^{\circ} 75$ de la Cámara de Senadores de la Nación Argentina. Recuperado de http://www1.hcdn.gov. ar/dependencias/dip/adebates.htm

Congreso de la Nación Argentina. (1903). Ley 4202. Vacunación antivariolosa obligatoria. Recuperado de http://www.infojus.gov.ar/index.php?kk_seccion=documento\&registr

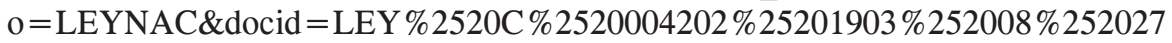

Congreso de la Provincia de Buenos Aires. (1887). Ley 1899. Cediendo a la Nación, los municipios de San José de Flores y Belgrano. Recuperado de http://www.gob.gba. ar/intranet/digesto/PDF/ley1899.pdf

Foucault, M. ([1974-75] 2000). Los anormales. Buenos Aires: Fondo de Cultura Económica.

Foucault, M. ([1976] 2000). Vigilar y castigar. Nacimiento de la prisión. (3 ${ }^{\text {a }}$ ed.). Nueva Criminología. Buenos Aires: Siglo XXI.

Foucault, M. ([1980] 1996). La vida de los hombres infames. Barcelona: Ariel.

Giné \& Partagás, J. (1875) Curso elemental de higiene pública y privada. (2a ed.). Barcelona: Librería de San Juan Bastinos e Hijos.

Gobierno de la Ciudad de Buenos Aires GCBA. (1996). Constitución de la Ciudad de Bue- 
nos Aires. Buenos Aires: Imprenta del Gobierno de la Ciudad.

Gobierno de la Ciudad de Buenos Aires GCBA. (2005). Buenos Aires hace cien años, a través de las postales. Buenos Aires a hundred years ago, through its postcards. Secretaría de Cultura: Comisión para la Preservación del Patrimonio Histórico Cultural de la Ciudad de Buenos Aires.

Honorable Concejo Deliberante. (1995). Evolución institucional del municipio de la ciudad de Buenos Aires. Buenos Aires: Ediciones del H. Concejo Deliberante.

Lévy, M. (1877). Tratado de higiene pública y privada. J. N. Crespo (trad.). Madrid: Establecimiento Tip. de R. Labajos.

Municipalidad de Buenos Aires. (1882). Memoria del Presidente de la Comisión Municipal al Concejo, correspondiente al ejercicio de 1881 febrero de 1882. Tomo I y II. Buenos Aires: M. Biedma.

Municipalidad de la Ciudad de Buenos Aires. (1906). Censo general de población, edificación, comercio e industrias de la Ciudad de Buenos Aires 1904. Buenos Aires: Municipalidad de la Ciudad de Buenos Aires, Compañía Sud-Americana de Billetes de Banco.

Penna, J. \& Madero, H. (1910). La Administración Sanitaria y Asistencia Pública de la Ciudad de Buenos Aires: estudio de los servicios de higiene y beneficencia pública, desde la época colonial hasta el presente. Tomos I y II. Municipalidad de la Capital: G. Kraft.

Santos, M. (1996). Metamorfosis del espacio habitado. Barcelona: Oikos-Tau.

Recepción: 03 de Julio de 2012

Evaluación: 20 de octubre de 2012

Aprobación: 22 de febrero de 2013 